\title{
Effect of Epinephrine on the Efficacy of the Internal Cardioverter-Defibrillator
}

\author{
João Sousa, MD, William Kou, MD, Hugh Calkins, MD, Shimon Rosenheck, MD, \\ Alan Kadish, MD, and Fred Morady, MD
}

To evaluate the effect of sympathetic activation on the efficacy of the implantable cardioverter-defibrillator (ICD) in converting ventricular tachycardia (VT) or ventricular fibrillation (VF), 32 patients who received an ICD because of life-threatening VT/VF underwent 1 week postimplant ICD testing both before and after infusion of 25 (16 patients) or 50 (16 patients) $\mathrm{ng} / \mathrm{kg} / \mathrm{min}$ of epinephrine for $\geq 12$ minutes. These infusion rates are known to result in plasma epinephrine concentrations comparable to mild-moderate stress. The patients' mean age was $63 \pm 10$ years; 26 had coronary artery disease, 2 had dilated cardiomyopathy and 4 had no evidence of structural heart disease. VT and VF were induced in 16 patients each by programmed stimulation or alternating current. Among the 16 patients with VT, the first ICD discharge (26 to $30 \mathrm{~J}$ ) was effective in 15 patients in the baseline state and in all 16 patients during epinephrine infusion. Among patients with VF, the first ICD discharge (26 to $30 \mathrm{~J}$ ) terminated VF in all patients in the baseline state, compared with 12 of 16 patients during epinephrine infusion (p <0.05). In 4 patients, VF was terminated during epinephrine infusion only by the second or third ICD discharge (30 J). In conclusion, physiologic increases in the plasma epinephrine concentration may increase the number and energy of shocks needed to terminate VF.

(Am J Cardiol 1992;69:509-512)

From the Department of Internal Medicine, Division of Cardiology, University of Michigan Medical Center, Ann Arbor, Michigan. Manuscript received June 17, 1991; revised manuscript received and accepted October 11, 1991 .

Address for reprints: Fred Morady, MD, University of Michigan Medical Center, 1500 E. Medical Drive, B1 F245, Ann Arbor, Michigan 48109 .
$\mathrm{T}$ wo recent reports described degeneration of sinus tachycardia to ventricular tachycardia (VT) when shocks from an internal cardioverter-defibrillator (ICD) occurred during physical exercise. ${ }^{1,2}$ This suggested that the sympathetic activation that accompanies exercise may have adverse effects on the response to ICD discharges. However, no prior studies have systematically examined the effect of exercise or sympathetic activation on the response to ICD shocks. Therefore, the purpose of this study was to evaluate the influence of sympathetic activation on the efficacy of the ICD in converting VT and ventricular fibrillation (VF). Sympathetic activation was induced with intravenous infusions of epinephrine at doses previously demonstrated to achieve plasma concentrations similar to those observed during mild to moderate physical exercise. $^{3}$

\section{METHODS}

Patients: This study consisted of 32 consecutive patients ( 24 men and 8 women, mean age \pm SD $63 \pm 10$ years) who underwent implantation of an ICD because of life-threatening VT or VF and who underwent testing to evaluate ICD function 1 week later. Twenty-six patients had coronary artery disease, 2 had a dilated cardiomyopathy and 4 had no evidence of structural heart disease. The mean left ventricular ejection fraction as determined by contrast ventriculography was $0.35 \pm$ 0.15 .

The clinical presentation was aborted sudden death in 21 patients and sustained VT accompanied by syncope or near-syncope in 11 patients. Among the patients with aborted sudden death, basclinc clectrophysiologic testing demonstrated inducible sustained monomorphic VT in 8 patients, sustained polymorphic VT in 4 patients and no inducible arrhythmias in 9 patients. Sustained monomorphic VT was inducible in all of the patients in whom the clinical presentation was sustained VT. Patients with inducible monomorphic VT failed serial electropharmacologic testing before ICD implantation.

ICD implantation: The ICD pulse generators and leads were manufactured by Cardiac Pacemakers, Inc. (St. Paul, Minnesota). A median sternotomy approach was used, with rate-sensing screw-in leads positioned on the anterior surface or outflow tract of the right ventricle and defibrillator patch electrodes on the lateral left ventricle and right atrium. Thirty-one patients received a Ventak (model 1550) ICD and 1 patient received a Ventak-P (model 1600).

An external cardioverter-defibrillator (Cardiac Pacemakers, Inc.) was used for intraoperative defibrilla- 


\begin{tabular}{|c|c|c|c|c|c|c|c|c|c|c|c|c|c|}
\hline \multirow[b]{2}{*}{ Pt. } & \multirow[b]{2}{*}{ HD } & \multirow[b]{2}{*}{ DFT } & \multicolumn{5}{|c|}{ Baseline } & \multicolumn{6}{|c|}{ During Epinephrine Infusion } \\
\hline & & & $\begin{array}{l}\text { Rhythm } \\
\text { Induced }\end{array}$ & $\begin{array}{c}\text { Duration } \\
\text { (s) }\end{array}$ & $\begin{array}{l}\text { No. of } \\
\text { Shocks }\end{array}$ & $\begin{array}{c}\text { Effective } \\
\text { Energy } \\
\text { (J) }\end{array}$ & $\begin{array}{l}\text { First Shock } \\
\text { Conversion }\end{array}$ & Epi & $\begin{array}{l}\text { Rhythm } \\
\text { Induced }\end{array}$ & $\begin{array}{c}\text { Duration } \\
\text { (s) }\end{array}$ & $\begin{array}{l}\text { No. of } \\
\text { Shocks }\end{array}$ & $\begin{array}{c}\text { Effective } \\
\text { Energy } \\
\text { (J) }\end{array}$ & $\begin{array}{l}\text { First Shock } \\
\text { Conversion }\end{array}$ \\
\hline 1 & CAD & - & $V T$ & - & 1 & 26 & + & 25 & VT & 18 & 1 & 26 & + \\
\hline 2 & CAD & 15 & VT & 17 & 1 & 26 & + & 25 & VT & 16 & 1 & 26 & + \\
\hline 3 & CAD & 20 & VT & 14 & 1 & 30 & + & 25 & VT & 18 & 1 & 30 & + \\
\hline 4 & CAD & 20 & VT & 15 & 1 & 26 & + & 25 & VT & 14 & 1 & 26 & + \\
\hline 5 & $\mathrm{CAD}$ & 10 & VT & 20 & 1 & 30 & + & 25 & VT & 18 & 1 & 26 & + \\
\hline 6 & CAD & 10 & VT & 14 & 1 & 26 & + & 25 & VT & 15 & 1 & 26 & + \\
\hline 7 & CAD & 10 & VT & 12 & 1 & 26 & + & 25 & $V T$ & 12 & 1 & 26 & + \\
\hline 8 & $C A D$ & 15 & $V T$ & 19 & 1 & 30 & + & 25 & $\mathrm{VT}$ & 18 & 1 & 30 & + \\
\hline 9 & CAD & 15 & VT & 9 & 1 & 26 & + & 25 & VT & 21 & 1 & 26 & + \\
\hline 10 & CAD & 25 & VT & 15 & 1 & 30 & + & 25 & VT & 13 & 1 & 30 & + \\
\hline 11 & CAD & 10 & VT & 13 & 1 & 30 & + & 50 & VT & 13 & 1 & 30 & + \\
\hline 12 & $C A D$ & 10 & VT & 14 & 1 & 26 & + & 50 & $V T$ & 14 & 1 & 26 & + \\
\hline 13 & $C A D$ & 10 & VT & 13 & 1 & 26 & + & 50 & $v T$ & 12 & 1 & 26 & + \\
\hline 14 & $C A D$ & 10 & VT & 13 & 2 & 30 & - & 50 & vT & 15 & 1 & 30 & + \\
\hline 15 & CAD & 15 & VT & 13 & 1 & 26 & + & 50 & VT & 12 & 1 & 26 & + \\
\hline 16 & CAD & 15 & VT & 15 & 1 & 26 & + & 50 & VF & 14 & 1 & 26 & + \\
\hline 17 & CAD & 15 & VF & 15 & 1 & 26 & + & 25 & VF & 14 & 1 & 26 & + \\
\hline 18 & $I D C$ & 15 & VF & 18 & 1 & 30 & + & 25 & VF & 16 & 2 & 30 & - \\
\hline 19 & NSHD & 15 & VF & 18 & 1 & 26 & + & 25 & VF & 23 & 2 & 30 & - \\
\hline 20 & CAD & 20 & VF & 14 & 1 & 26 & + & 25 & VT & 15 & 1 & 26 & + \\
\hline 21 & $C A D$ & 15 & VF & 11 & 1 & 26 & + & 25 & VF & 14 & 1 & 26 & + \\
\hline 22 & NSHD & 10 & VF & 14 & 1 & 26 & + & 25 & VF & 11 & 1 & 26 & + \\
\hline 23 & NSHD & 10 & VF & 11 & 1 & 26 & + & 50 & VF & 12 & 1 & 26 & + \\
\hline 24 & $C A D$ & 5 & VF & 10 & 1 & 30 & + & 50 & VF & 10 & 1 & 20 & + \\
\hline 25 & $C A D$ & 10 & VF & 12 & 1 & 26 & + & 50 & VF & 12 & 1 & 26 & + \\
\hline 26 & NSHD & 10 & VF & 12 & 1 & 26 & + & 50 & VF & 14 & 1 & 26 & + \\
\hline 27 & CAD & 15 & VF & 12 & 1 & 26 & + & 50 & VF & 11 & 3 & 30 & - \\
\hline 28 & IDC & 20 & VF & - & 1 & 30 & + & 50 & VF & 14 & 1 & 30 & + \\
\hline 29 & $C A D$ & 20 & VF & 14 & 1 & 30 & + & 50 & VF & 10 & 1 & 30 & + \\
\hline 30 & $C A D$ & 15 & VF & 11 & 1 & 26 & + & 50 & VF & 13 & 1 & 26 & + \\
\hline 31 & CAD & 10 & VF & 13 & 1 & 26 & + & 50 & VF & 13 & 1 & 26 & + \\
\hline 32 & CAD & 15 & VF & 20 & 1 & 26 & + & 50 & VF & 16 & 2 & 30 & ${ }^{*}-$ \\
\hline
\end{tabular}

tion testing. Defibrillation threshold was defined as the minimum energy required to terminate VF. In 4 patients, VF was not inducible and only the minimum energy to convert VT was recorded. To determine the defibrillation threshold, alternating current or rapid pacing was used to induce VF and the defibrillator pulse was delivered after approximately 10 seconds. The defibrillation threshold was $5 \mathrm{~J}$ in 1 patient, $10 \mathrm{~J}$ in 12 patients, $15 \mathrm{~J}$ in 12 patients, $20 \mathrm{~J}$ in 5 patients and 25 Joules in 1 patient (Table I).

ICD conversion test: ICD conversion tests were performed 1 week after implantation of the ICD, after informed consent had been obtained. The study protocol was approved by the Human Research Committee of the University of Michigan. With use of a femoral or internal jugular vein, a quadripolar electrode catheter was positioned at the right ventricular apex under fluoroscopic guidance. The surface electrocardiographic leads and intracardiac electrogram were recorded on a Siemens-Elema Mingograf 7 recorder. A programmable stimulator (Bloom Assoc., Ltd.) was used for pro- grammed stimulation using pulses $2 \mathrm{~ms}$ in duration at twice the diastolic threshold.

Whenever possible, the ICD shock strength was programmed to be $\geq 10 \mathrm{~J}$ greater than the intraoperative defibrillation threshold. ${ }^{4} \mathrm{~A}$ baseline conversion test was then performed after VT or VF was induced with programmed stimulation or alternating current. After the initial conversion test, epinephrine was infused at a rate of 25 and $50 \mathrm{ng} / \mathrm{kg} / \mathrm{min}$ in 16 patients each. These infusion rates have previously been shown to achieve systemic concentrations comparable with the plasma epinephrine concentrations that occur during mild to moderate exercise. ${ }^{3}$ Epinephrine was infused for 12 minutes in order to achieve a steady state, as previously described. ${ }^{5}$ Using programmed stimulation or alternating current, VT or VF was then reinduced. An effort was made to induce the same type of arrhythmia as had been induced in the baseline conversion test. During both conversion tests, the type and duration of the induced ventricular arrhythmia, the energy and number of shocks, and the rhythms that occurred after the 
shocks were recorded. Nonconversion was defined as the persistence of sustained VT or VF after an ICD discharge. Ventricular arrhythmias after conversion were defined as idioventricular rhythm if the rate was $<100$ beats $/ \mathrm{min}$ or VT if the rate was $\geq 100$ beats $/ \mathrm{min}$.

In 5 patients, the venous plasma concentrations of epinephrine and norepinephrine were measured in the baseline state and 1 minute after the baseline ICD discharge using a single isotope radioenzymatic assay. ${ }^{6}$

Statistical analysis: Statistical analysis was performed using Fisher's exact test or Student's $t$ test. A p value $<0.05$ was considered significant.

\section{RESULTS}

Baseline conversion tests (Table I): In the baseline state, before arrhythmia induction, the mean heart rate was $88 \pm 19$ beats/min. During the baseline ICD conversion test, sustained monomorphic $V T$, which had a mean cycle length of $294 \pm 42 \mathrm{~ms}$, and VF, which had a mean cycle length of $191 \pm 16 \mathrm{~ms}$, were induced in 16 patients each. The first ICD shock ( $26 \mathrm{~J}$ in 23 patients and $30 \mathrm{~J}$ in 9 patients) was successful in converting 15 of 16 episodes of VT and all episodes of VF to sinus rhythm. One episode of sustained monomorphic VT was converted to sinus rhythm by a second discharge of $30 \mathrm{~J}$ after a $26 \mathrm{~J}$ discharge had failed.

Conversion tests during epinephrine infusion (Table I): During infusion of epinephrine, before arrhythmia induction, the mean heart rate increased to $93 \pm 17$ beats/min (not significantly different from baseline). Sustained monomorphic VT, which had a mean cycle length of $287 \pm 41 \mathrm{~ms}$, and VF, which had a mean cycle length of $184 \pm 20 \mathrm{~ms}$, were again induced in 16 patients each. These mean cycle lengths did not differ significantly from the mean cycle lengths of VT and VF induced in the baseline state. The first ICD discharge was successful in converting 16 of 16 episodes of VT, but was successful in converting only 12 of 16 episodes of VF ( $p<0.05$ compared with baseline). A second or third shock at the same or higher energy was required in 3 patients, and VF converted to sustained VT which required a second shock to terminate in 1 patient. There was no significant difference in the success rate of defibrillation between the 25 and $50 \mathrm{ng} / \mathrm{kg} / \mathrm{min}$ infusion rates of epinephrine (3/5 VF episodes vs $9 / 11$ VF episodes, respectively). There was no significant difference in the duration of VF (from induction to first shock) between the successful and unsuccessful attempts at defibrillation.

Rhythm after conversion: Immediately after conversion, the mean sinus rate was $77 \pm 19$ beats during the baseline conversion test and $101 \pm 17.5$ beats $/ \mathrm{min}$ during the epinephrine conversion test $(p=0.05)$. After the successful ICD discharge, there was an idioventricular rhythm in 7 patients (rate $69 \pm 11$ beats/min lasting for $7.5 \pm 2.2$ seconds) and nonsustained VT in 5 patients (rate $137 \pm 18$ beats $/ \mathrm{min}$, lasting $7 \pm 3.1 \mathrm{sec}-$ onds) during the baseline test, and there was an idioventricular rhythm in 7 patients (rate $77 \pm 13$ lasting for $10.2 \pm 5$ seconds) and nonsustained VT in 10 patients (rate $130 \pm 22.5$ lasting for $10 \pm 7$ seconds) during the epinephrine conversion test. There was no significant difference in the incidence, rate or duration of these transient ventricular arrhythmias after shock during baseline or during epinephrine infusion tests.

Plasma epinephrine concentrations: In 5 patients, the plasma concentrations of epinephrine and norepinephrine were measured in the baseline state and immediately after the first ICD discharge. There was a significant increase in plasma epinephrine concentration, from a baseline mean of $78 \pm 48$ to $150 \pm 61 \mathrm{pg} / \mathrm{ml}$ after the ICD discharge $(p=0.04)$. There was no significant change in mean plasma norepinephrine concentration after the ICD discharge (954 \pm 854 vs $1,091 \pm$ $929 \mathrm{pg} / \mathrm{ml}$ ).

\section{DISCUSSION}

Effects of sympathetic activation on efficacy of the ICD: This study demonstrates that sympathetic activation may impair the efficacy of the ICD in terminating VF. Infusion of epinephrine at rates that achieve plasma concentrations comparable to those that occur endogenously during exercise resulted in a significant reduction in efficacy of the first ICD discharge in terminating VF, from 100 to $75 \%$. Although VF was always successfully terminated during infusion of epinephrine by a second or third ICD discharge that was of either the same or only slightly greater strength than the first discharge, the failure of the first ICD discharge to defibrillate is consistent with an increase in the energy required to terminate VF. The energy required to defibrillate has been shown to be a continuous probability function instead of a single discrete defibrillation threshold. ${ }^{7}$ Therefore, an increase in the energy required to defibrillate is associated with a diminished probability that shocks of a given strength will consistently be effective.

In contrast to VF, all episodes of VT underwent successful cardioversion with the first ICD discharge during the infusion of epinephrine. However, the absence of a discernible effect of epinephrine on the efficacy of the ICD in converting VT does not rule out an effect of epinephrine on the energy required to terminate VT. Because the energy required to terminate VT is generally lower than the energy required to terminate VF, the 26 to $30 \mathrm{~J}$ shock delivered by the ICD may have provided a larger margin for successful conversion of VT compared with VF.

Results of prior studies: Experimental studies of the effect of catecholamines on the energy required to defibrillate have had conflicting results. In anesthetized dogs, isoproterenol was found to decrease the defibrillation threshold. ${ }^{8}$ In a study performed in pigs, isoprotcrcnol decreased the defibrillation threshold when single pulses were used to defibrillate, but had no effect on the defibrillation threshold when sequential-pulse defibrillation was used. ${ }^{9}$ This study also showed that phenylephrine had no effect on the defibrillation threshold. In another study in dogs, epinephrine was found not to have a significant effect on the energy required to defibrillate. ${ }^{10}$ However, in this latter study, epinephrine was ad- 
ministered only after VF had been induced, ${ }^{10}$ whereas isoproterenol was infused before the induction of VF in the other studies. ${ }^{8,9}$

The discrepancy between the results of the present study and the results of prior experimental studies may be attributable to species differences, differences in the degree of sympathetic activation, or to differences between the effects of epinephrine and isoproterenol. In addition, most subjects in this study had underlying heart disease, whereas the experimental studies used animals that did not have heart disease; it is possible that sympathetic activation has differential effects on the energy required to terminate VF, depending on the presence or absence of heart disease.

Effect of ICD discharges on the plasma epinephrine concentration: Direct-current countershocks of 200 to $300 \mathrm{~J}$ delivered to the chest to convert sustained VT have been demonstrated to result in approximately a fivefold increase in the plasma epinephrine concentration. ${ }^{11}$ In contrast, the 26 to $30 \mathrm{~J}$ ICD shocks in the present study resulted in only a twofold increase in the plasma epinephrine concentration. The greater degree of sympathetic activation associated with the external countershocks may be related to the higher energy of these shocks compared with the ICD shocks.

In a previous study, ${ }^{12}$ epinephrine infused in the same dosages as in the present study resulted in mean arterial plasma epinephrine concentrations of $862 \pm$ 226 and $1,374 \pm 477 \mathrm{pg} / \mathrm{ml}$. However, arterial plasma concentrations of epinephrine generally are approximately twofold higher than venous plasma concentrations of epinephrine, ${ }^{13}$ which were measured in this study. Taking into account the difference between arterial and venous concentrations of epinephrine, the plasma epinephrine concentrations achieved with the 25 and $50 \mathrm{ng} / \mathrm{kg} / \mathrm{min}$ infusions used in this study, nevertheless, would be expected to be significantly higher than the plasma epinephrine concentration resulting from the discharge of the ICD. Whether the lesser degree of sympathetic activation that occurs after an ICD discharge is sufficient to alter the energy required to defibrillate remains to be determined. If so, it is possible that an ineffective ICD discharge might lower the probability that subsequent ICD discharges will be effective in terminating VF.

Rhythm after conversion: The incidence of transient ventricular arrhythmias after conversion was similar in the baseline state and during epinephrine infusion. These rhythms were generally slow ( $\leq 130$ beats/min) and short-lasting ( $\leq 10$ seconds) and therefore not likely to be sensed by the ICD.

Clinical implications: This study has demonstrated that epinephrine infusions that achieve plasma concentrations of epinephrine comparable to those occurring during mild to moderate physical exercise can have a significant effect on the number of ICD shocks needed to terminate VF. Therefore, in patients with a history of VF during exercise, ICD conversion tests ideally should be performed either during exercise or epinephrine infusion. The results of this study also suggest that other types of stress that increase sympathetic tone also may have a deleterious effect on the efficacy of the ICD in terminating VF. This may be a potential explanation for sudden death in patients who have received an ICD. In patients with implantable defibrillators who may be prone to having VF in the setting of sympathetic activation, treatment with a $\beta$-adrenergic blocking agent may improve the efficacy of the ICD in terminating VF.

\section{REFERENCES}

1. Gottlieb C, Rosenthal M, Marchlinski FE. Initiation of a sustained ventricular arrhythmia resulting from $\mathrm{R}$ wave-synchronous AICD discharge. Am Heart $J$ 1988;115:915-917.

2. Kou WH, Kirsh MM, Stirling MC, Kadish AH, Orringer CE, Morady F. Provocation of ventricular tachycardia by an automatic implantable cardioverter defibrillator. Am Heart $J$ 1990;120:208-210.

3. Stratton JR, Pfeifer MA, Ritchie JL, Halter JB. Hemodynamic effects of epinephrine: concentration-effect study in humans. J Appl Physiol 1985;58: 1199-1206.

4. Marchlinski FE, Flores B, Miller JM, Gottlieb CD, Hargrove WC. Relation of the intraoperative defibrillation threshold to successful postoperative defibrillation with an automatic implantable cardioverter defibrillator. Am J Cardiol 1988;62: 393-398.

5. Cohen G, Holland B, Sha J, Goldenberg M. Plasma concentrations of epinephrine and norepinephrine during intravenous infusions in man. $J$ Clin Invest 1959;38:1935-1941.

6. Evans MI, Halter JB, Porte D Jr. Comparison of double- and single-isotopic enzymatic derivative methods for measuring catecholamines in human plasma. Clin Chem 1978:24:567-570.

7. Echt DS, Black JN, Barbey JT, Coxe DR, Cato E. Evaluation of antiarrhythmic drugs on defibrillation energy requirements in dogs-sodium channel block and action potential prolongation. Circulation 1989;70:1106-1117.

8. Ruffy R, Schechtman K, Monje E. $\beta$-adrenergic modulation of direct defibrillation energy in anesthetized dog hearts. Am J Physiol 1985;248:H674-H677. 9. Rates MF, Sharma AD, Klein GJ, Szabo T, Jones DL. Adrenergic effects on internal cardiac defibrillation threshold. Am J Physiol 1987;253:H500-H506. 10. Yakatis RW, Ewy GA, Otto CW, Taren DL, Moon TE. Influence of time and therapy on ventricular defibrillation in dogs. Crit Care Med 1980:8:157-163.

11. Morady F, DiCarlo LA, Halter JB, deBuitleir M, Krol RB, Baerman JM. The plasma catecholamine response to ventricular tachycardia induction and external countershock during electrophysiologic testing. $J \mathrm{Am}$ Coll Cardiol 1986;8:584-591.

12. Morady F, Nelson SD, Kou WH, Pratley R, Schmaltz S, deBuitleir M Halter JB. Electrophysiologic effects of epinephrine in humans. J Am Coll Cardiol 1988;11:235-244.

13. Halter JB, Pflug E, Tolas AG. Arterial-venous differences of plasma catecholamines in man. Metabolism 1980;29:9-12. 